\title{
HEAT TRANSFER ENHANCEMENT OF NANO FLUIDS -A REVIEW
}

\author{
B. Kirubadurai ${ }^{1}$, P.Selvan ${ }^{2}$, V.Vijayakumar ${ }^{3}$, M.Karthik ${ }^{4}$ \\ ${ }^{1}$ Assistant professor, Sri Shakthi College of Engineering, Coimbatore \\ ${ }^{2}$ Assistant professor' SNS College of Engineering, Coimbatore \\ ${ }^{3}$ Assistant professor, P.A College of Engineering and Technology, Coimbatore \\ ${ }^{4}$ Assistant professor, Sri Shakthi College of Engineering, Coimbatore
}

\begin{abstract}
Thermal conductivity is considered important factor for rapid cooling and heating application. Base heat transfer fluid normally having low thermal conductivity, so we goes to Nano fluid for increases the heat transfer rate. Nano fluid is nanometre sized particle such as metal, oxide, and carbide etc., dispersed into base heat transfer fluid. In this paper shows varying factor affecting the thermal conductivity of Nano fluid at different conditions. All researcher tried to increase the heat transfer rate by considering thermal conductivity Nano fluid. Thermal conductivity is increased with increasing concentration of metal particle within critical limit. Thermal conductivity is affected by the following parameters like shape, size, clustering, collision, porous layer, melting point of nanoparticle etc., controlling this type of parameters to increase the thermal conductivity of Nano fluid. Nano fluid is advanced heat transfer fluid for next generation.
\end{abstract}

Keywords: Nano fluid; thermal conductivity; heat transfer rate; clustering; porous layer.

\section{INTRODUCTION}

A Nano fluid is a fluid contain nanometre size metal particle, called nanoparticles. These fluid are engineering colloidal suspension of nanoparticle in base fluid. Nanoparticle used in Nano fluids are typically made of metals, oxides, carbides or carbon Nano tube. Common base fluids include water, ethylene glycol and oil. They exhibit high thermal conductivity and convective heat transfer coefficient compared to the base fluid.

\section{SYNTHESIS OF NANO FLUID}

Nano fluids are supplied by two methods called the one-step and two-step methods. One step technique, the first step is production of nanoparticle and second step is the dispersion of the nanoparticle in a base fluid. Second technique is a mass production method of Nano fluids by utilising the inert gas condensation technique. The main disadvantage of two step method is form cluster during preparation of Nanoparticle.

\section{NEEDS OF NANO FLUID}

- Due to Nano size particles, pressure drop is minimum.

- High thermal conductivity of nanoparticle increases the heat transfer rate.

- Successfully employed Nano fluid will lead to lighter and smaller heat exchanger.

- Drastic change in the properties of base fluid, by suspension of Nano fluids.

- Heat transfer rate is increases due to large surface volume of nanoparticle in base fluid.

- Nano fluid are most suitable for rapid heating and cooling system.
- Due to Nano size particle, fluid is considered as integral fluid.

\section{APPLICATION OF NANO FLUID}

Nano fluid can be used to cool automobile engine and welding equipment and cool high heat flux device such as high power microwave tube, and high power laser diode array. Nano fluid could flow through the tiny passage in MEMS to improve the efficiency.

Some common applications are:

- Engine cooling

- Engine transmission oil

- Boiler exhaust flue gas recovery

- Cooling of electronic circuit

- Nuclear cooling system

- Solar water heating

- Refrigeration

- Defence and space application

- Thermal storage

- Bio-medical application

- Drilling and lubrication

\section{LITERATURE SURVEY}

[1]. L.B. Mapa et al: Measured enhanced thermal conductivity of $\mathrm{Cu}$-water Nano fluid using shell and tube heat exchanger. Where the dimension of heat exchanger is $240 \times 24 \times 0.25 \mathrm{~mm}$, using 37 tubes. The outcome of this analysis is rate of heat transfer is increases with increasing flow rate and also its concentration. By nanoparticle dispersed into de-ionized base fluid a better enhancement is achieved. 
[2]. J. Koo et al: Investigated the nanoparticle collision and deposition in the surface wall with help of micro channel heat sink. Which has the dimension of $1 \mathrm{cmx} 100$ micometerx300micrometer, water-Cuo and Cuoethylin glycolNano fluids are through the micro channel heat sink. Theyare investigated the base fluid should possess high prandle number, and get enhanced heat transfer rate by minimize particle-particle and particle-wall collision. Viscous dissipation effect is important of narrow channel, because Nuselt number high for high aspect ratio channel.

[3]. Shung-Wen Kang et al: Studied about the relation between thermal resistance-size of nanoparticle with help of 211 micrometre*217 micrometre sized and deep grooved circular heat pipe and heat pipe maintain $40^{\circ} \mathrm{C}$ temperature.They are finalized thermal resistance is directly proportional to the size of the nanoparticle. Maximum reduction of thermal resistance by using $10 \mathrm{~nm}$ sized particles, because particle size is increasing the wall temperature also increases. So small sized particle suitable for enhanced heat transfer rate. Thermal resistance is decreases with increasing heat and concentration of Nano particle.

[4]. Shuichi Torri: Investigated convective heat transfer co efficient of diamond based Nano fluid by using heat tube apparatus. Specification of tube is $4.3 \mathrm{~mm}, 4 \mathrm{~mm}$ outer and inner diameter respectively, and applied $100 \mathrm{~W}$ power unofomly. They are showed the heat transfer coefficient is increases with increasing concentration and Reynolds number of Nano fluid. But at the same time increased the pressure drop with increasing concentration of Nano particle.

[5]. S.J.Kim et al: Investigated formation of porous layer and wettability of Nano fluid using critical heat flux experiment and SEM images. They are used three different type of nanoparticles with different diameters such as $\mathrm{Al}_{2} \mathrm{O}_{3}$ (110-210nm), $\mathrm{SiO}_{2}$ (20-40nm) and $\mathrm{ZrO}_{2}(110-210)$. They are showed boiling is main factor to affect the heat transfer rate of Nano fluid. Due to nucleate boiling nanoparticle deposited on wall, so the porous layer is formed on the wall. Porous layer directly consequence for creating wettability, cavity and roughness of the surface wall. So heat transfer rate decreased due to boiling of Nano fluid.

[6]. PaisarnNaphon et al: Investigated the thermal efficiency of heat pipe using titanium-alcohol Nano fluid, heat pipe dimensions are $60 \mathrm{~mm}$ and $15 \mathrm{~mm}$ length and outer diameter respectively. The thermal efficiency increases with increasing tilt angle within $60^{\circ}$ angle and concentration of nanoparticle.

[7]. Anil Kumar et al: studied the heat transfer enhancement of fin, utilizing $\mathrm{AL}_{2} \mathrm{O}_{3}$-Water Nano fluid analysed using CFD. Rayleigh number increases due to Brownian motion, ballistic phonon transport, clustering and dispersion effect of nanoparticle. At high Rayleigh number flow rate at centre of the circulation is increasing, so temperature is drop from centre of fin. Volume of the circulation increases the velocity at centre is increases as the result of increasing the solid-fluid heat transportation. Low aspect ratio fin is suitable for heat transfer enhancement, because heat affected zone is less.

[8]. Yu-Tang chen: Investigated the thermal resistance of heat pipe using Ag-DI Water Nano fluid, heat pipe made as $200 \mathrm{~cm} \times 3 \mathrm{~mm}$ length and thickness respectively. Heat resistance is increases with increasing concentration of Nano fluid up to 50ppm. Due to wettability of nanoparticle various geometry of wick is created on heat pipe.

[9]. Eed Abdel Hafez Abdel-hadi et al: Investigated the heat transfer analysis of vapour compression system using $\mathrm{CuO}$ R134a Nano fluid, test section made of copper horizontal tube and heat is applied $10-40 \mathrm{KW} / \mathrm{m}^{2}$. Heat flux, concentration, and size particle is important factor to enhance the heat transfer rate of Nano fluid. Heat transfer rate is increases with increasing heat flux, up to $55 \%$ of concentration of Nano fluid and up to $25 \mathrm{~nm}$ sized particles.

[10]. Somchaiwongwises et al: Investigated heat transfer enhancement and flow characteristic of $\mathrm{Al}_{2} \mathrm{O}_{3}$-Water Nano fluid using micro channel heat sink. The dimension of test section is $5 \times 5 \mathrm{~mm}$ and $50 \mathrm{~W}$ heat is applied. Heat transfer is enhanced at high Reynolds number and high concentration of Nanofluid, because at high Reynolds number wall temperature is decreases and pressure drop is increased.

[11]. Yannar et al: Investigated the flow and heat transfer characteristic of spiral pipe heat exchanger using different type of Nano fluid with different concentration such as $\mathrm{Al}_{2} \mathrm{O}_{3}$-water, $\mathrm{TiO}_{2}$-water, $\mathrm{CuO}$-water Nano fluid with $1 \%$, $1 \%$ and $3 \%$ concentration respectively. Test section made of copper tube had the ratio of pitch per diameter is 7 , mean hydraulic diameter is $30 \mathrm{~mm}, 10 \mathrm{~mm}$ diameter and $1600 \mathrm{~mm}$ length. Heat transfer enhanced $28 \%$ at $0.8 \%$ concentration of Nano fluid, due to high concentration shear stress of Nano fluid is increased. Heat transfer enhancement is high in spiral pipe compared with circular pipe, because the pressure drop is high in spiral pipe. Heat transfer co efficient is decreases when axial distance of Nano fluid is increasing, because formation of boundary layer.

[12]. Nawaf.H et al: Investigated the thermal performance of air-water heat exchanger using $\mathrm{TiO}_{2} \mathrm{Nano}$ fluid. Air duct dimension is $100 \times 30 \times 300 \mathrm{~mm}$, and water flow through inside the pipe had $5 \mathrm{~mm}$ radius and 300 length. Air through external surface of pipe as the result of heat is transferred. Heat transfer coefficient is increases with increasing Reynolds number at constant volume of friction up to $0.6 \%$ and increasing concentration at constant Reynolds number up to 1000 , but at high concentration needs high pumping power. Nessult number is increases with increasing Reynolds number, high heat transfer is occurred in this condition, but decreases when axial distance is increasing at aerofoil particular angle of attack. Maximum heat is transferred at $0-100^{\circ}$ angle of aerofoil. 
[13]. H.Niazmand et al: Studied convective heat transfer of carbon Nano tube-water Nano fluid using isothermally heated $90^{\circ}$ curved pipe, and set an inlet temperature of fluid and wall is $293 \mathrm{~K}$ and $363.15 \mathrm{~K}$. They analysed the relation between peclet numbers and enhance heat transfer rate, inside the curve flow accelerate along the outer wall region due to centrifugal force, so maximum velocity shifted towards the outer wall of pipe and forming secondary flow. Secondary flow is formed due to curvature effect, so enhanced heat transfer by the secondary flow formation. Curvature effect is more promoted at Peclet number. Minimum intensity of flow occur at middle of the curve, due to high Reynolds number amplified the centrifugal force. Monolayer is formed at solid particle interface, so thermal conductivity of monolayer is much greater compared with bulk fluid.

[14]. Manag et al: Investigated the friction factor and heat transfer rate of $\mathrm{CuO}$-Water and $\mathrm{Al}_{2} \mathrm{O}_{3}$-water Nano fluid using micro channel heat sink. Dimension of test section is 100x100x20000micrometter, assumed steady state laminar flow occurred, neglected the radioactive heat transfer and adiabatic constant heat flux applied at bottom of heat sink is $5000 \mathrm{~W} / \mathrm{cm}^{2}$. As the result of increasing nusselt number with increasing the Reynolds number and concentration but decreased the friction factor of Nano fluid. Compared the $\mathrm{CuO}$-water and $\mathrm{Al}_{2} \mathrm{O}_{3}$-water Nano fluids the $\mathrm{CuO}$-water Nano fluid showed better enhancement and low friction factor.

[15]. Praveen al: Studied the heat transfer enhancement $\mathrm{Al}_{2} \mathrm{O}_{3}$-water Nano fluid. Heat transfer rate is calculated with various temperature $\left(25^{0}-80^{0}\right)$, various concentration $(0.01$ $0.5 \%)$ and various Reynolds number (2500-5000). Heat transfer rate is increased with increasing Reynolds number and concentration of Nano fluid but decreased when increasing inlet temperature of Nano fluid.

[16]. Mahdi Pirhayati et al: Studied the pressure drop of Nano fluid at an inclined tube, tube having dimension of $12 \times 120 \times 0.9 \mathrm{~mm}$, cross section area of tube is circular and uniformly heat is applied on the surface of tube is $3200 \mathrm{~W} / \mathrm{m}^{2}$. As the result of pressure drop is increased with increasing the Reynolds number and concentration of Nano fluid. Inclined tube having less pressure drop compared with horizontal tube and minimum pressure drop is occurred, whenthe tube is inclined at $30^{\circ}$ angle.

[17]. O Manna et al: Investigated the thermal conductivity enhancement of SiC-water Nano fluid using transient hot wire device. Thermal conductivity of Nano fluid is increased with increasing the concentration of nanoparticle, $26 \%$ of maximum thermal conductivity is obtained when using $0.8 \%$ concentration of Nano fluid. Mechanically milled nanoparticles having high heat transfer enhancement. Nanoparticle volume and shape is important factor to enhance the thermal conductivity of Nano fluid, at $27 \mathrm{~nm}$ sized nanoparticle enhanced $12 \%$ of thermal conductivity Nano fluid.
[18]. Kavitha et al: Investigated thermal conductivity enhancement of $\mathrm{TiO}_{2}$-water Nano fluid using transient hot wire device. Thermal conductivity of nanoparticle is increased when using spherical shaped nanoparticle, and thermal conductivity is dependent many parameter such as size, shape, stability, and coating of nanoparticle. Spherical shaped nanoparticle having high heat transfer rate compared with other shaped nanoparticle.

[19]. Mohamed hadi et al: Studied enhancement of heat transfer rate by considering clustering effect of nanoparticle. The heat transfer rate is increases with increasing the concentration of nanoparticle, due to high concentration clustering is occur. Clustering is increased the heat transfer rate of Nano fluid at certain contact time of particle, but cluster still possess the problem of agglomeration. Agglomeration can reduce to use micro sized particle.

[20]. Alpesh V Mehta et al: Investigated the thermal conductivity enhancement of $\mathrm{Al}_{2} \mathrm{O}_{3}$-water Nano fluid using Mimi heat exchanger. As the result of thermal conductivity of Nano fluid is increased with increasing temperature. Heat transfer coefficient of Nano fluid dependents on following parameter such as thermal conductivity, density, heat capacity and viscosity of Nanofluid. High heat conductance occurs at Brownian motion and collision of Nanoparticle, irregular motion is created in small size of nanoparticle because of poor stability but small particle collide easily so increase the heat transfer rate with in critical limit.

[21]. PareshMachar et al: Investigated the heat transfer enhancement of $\mathrm{TiO}_{2}$-water Nano fluid using automobile radiator, its having 34 vertical tube with elliptical cross section and temperature is maintained at $37-49^{\circ} \mathrm{C}$. As the result of enhanced heat transfer rate by increasing concentration, flow rate and Brownian motion of nanoparticle.

[22]. D.B. Shelke et al: Investigated the heat transfer enhancement of shell and tube heat exchanger using Nano fluid under the turbulent flow condition. Pipe dimension is considered $1 \mathrm{mx} 11 \mathrm{mmx} 0.5 \mathrm{mmx} 27 \mathrm{~m}$, Assumed counter flow heat exchanger. Enhanced heat transfer rate with increasing flow rate, concentration, thermal conductivity, collision and turbulent flow of Nano fluid. Flow rate is increased with increasing the Reynolds number, nusselt number and pressure drop of Nano fluid.

\section{DISCUSSION}

Various authors have performed the experimental investigation related to heat transfer enhancement and it's affecting factors by using $\mathrm{Al}_{2} \mathrm{O}_{3}, \mathrm{CuO}, \mathrm{TiO} 2, \mathrm{ZrO} 2, \mathrm{Ag}, \mathrm{SiC}$ and Diamond nanoparticle. Amongst all $\mathrm{CuO}$ and $\mathrm{Al}_{2} \mathrm{O}_{3}$ are frequently used for higher thermal conductivity, but many type of nanoparticle using to enhance the heat transfer rate at different application, and discussed many factor affecting the heat transfer rate of Nano fluid. Mixing is important for enhancement of heat transfer rate, so ultrasonic mixture is suitable for enhance thermal conductivity of nanoparticle 


\section{CONCLUSIONS}

- Heat transfer rate increases with increasing concentration of nanoparticle.

- Heat transfer rate is directly proportional to the Reynolds number and peclet number of Nano fluid.

- The fine grade of Nano particles increases the heat transfer rate but it's having poor stability.

- Clustering and collision of nanoparticles is main factor to affect the heat transfer rate of Nano fluid.

- Concentration of nanoparticles increases the pressure drop of Nano fluid.

- Spherical shaped nanoparticles increases the heat transfer rate of Nano fluid compared with other shaped nanoparticles.

- Boiling was to reduce the enhancement of heat transfer rate.

- $\quad$ Spiral pipe having higher heat transfer rate compared with the circular plain tube.

- Inclined tube possess the low pressure drop compared with horizontal tube.

\section{REFERENCES}

[1] L.B.Mapa, Sana Mazhar, Heat transfer in mini heat exchanger using Nano fluids. IL/IN sectional conference.

[2] J.Koo, C.Kleinstrecer, Laminar Nano fluid flow in micro heat sink. International journal of heat and mass transfer 48(2005).

[3] Shung-Wei Kang, Wei-Chiang Wei, Sheng-Hong Tsai, Shih-Yu YANG, Experimental investigation of silver Nano fluid on heat pipe thermal performance, Applied thermal engineering 26(2006).

[4] Shuichi Torii, Experimental study on convective heat transfer of aqueous suspension of Nano diamond particle, International symposium on Eco Topia science 07 (2007).

[5] S.J.Kim, I.C. Bang, J.Buongiorno, and, and L.N.Hu, Study of pool boiling and critical heat flux enhancement in Nano fluid.bullletin of the polish academy of sciences technical science.vol55,no 2,2007.

[6] PaisarnNaphon, Pichai Assad among Kol, TeerapongBorirak, Experimental investigation of titanium Nano fluid on the heat pipe thermal efficiency, International communication in HMT 35 (2008).

[7] S.H.Anil Kumar and G.Jilani, convective heat transfer enhancement in an enclosure with fin utilizing Nano fluid, International journal of aerospace and mechanical engineering.

[8] Yu-Tang Chen, Experimental study of silver Nano fluid on heat pipe thermal performance, Journal of marine science and technology, vol18, No.5 pp.731734.

[9] Eed Abdel-Hafer ABDEL-Hadi, Sherif Handy Taher, Abdel Hamid Mohamed Torki, and Samar sabryHauad, Heat transfer analysis of vapour compression system using Nano Cuo-R134a.
International conference on advanced materials engineering vol. 15(2011).

[10] WeerapunBuangthongsuk and SomchaiWongwises, Heat transfer enhancement and flow characteristic of alumina- water Nano fluid flowing through a micro channel heat sink. The second TSME International conference on mechanical engineering. 19-21 October 2011.

[11] Yanuar, N.Putra, Gunawan S.M.Bagi, Flow and convective heat transfer characteristic of spiral pipe for Nano fluid. IJRRAS 7(3).June 2011.

[12] Nawaf H. Saeid and Tan HengChaia, Investigation of thermal performance of air to water heat exchanger using Nano fluid, IIUM Engineering journal special issue mechanical engineering, 2011.

[13] E.Ebrahiminia- Bajestan, H.Niazmand, Convective heat transfer of Nano fluid flow through an isothermally heated curved pipe. Iranian journal of chemical engineering vol.8 no.2, (2011).

[14] Manay E, Salein B, Yilmaz M, Gelis Thermal performance analysis of Nano fluid in micro channel heat sinks. World academy of Science, Engineering and Technology vol. 67 (2012).

[15] Anchupogu Praveen, penugonda Suresh babu, Venkata Ramesh Manila, Analysis on heat transfer in Nano fluid for alumina-water. International journal of advanced scientific research and technology issue 2, volume 2(April 2012).

[16] Mahdi Pirhayati, Mohamed Ali AkharanBehabadimortezakhayat, Pressure drop of Cuo-base Nano fluid flow inside an inclined tube. International journal of advances in engineering and technology. November 2012.

[17] O Manna, S.K.Singh and G Paul, Enhanced thermal conductivity of Nano silicon carbide dispersed water based Nano fluid. Indian academy of sciences.vol 35, no 5.octobet 2012 pp.707-702.

[18] Kavitha.T, Rajendren.A, Durairajen.A, S.Syedabuthahir. Advanced heat transfer enhancement using titanium oxide-water based Nano fluid. IJMIEVOL 2.ISSUE 4.2012. 